\title{
Explanatory Study of Women Working in the Management of Universities
}

\author{
*Syeda Qudsia Batool ${ }^{1}$, M. A Sajid ${ }^{2}$, Hassan Raza ${ }^{3}$ \\ ${ }^{1}$ DHQ Hospital Kotli A J \& K, Pakistan \\ ${ }^{2}$ University of AJ\&K Kotli A J \& K, Pakistan \\ ${ }^{3}$ Allama Iqbal Open University, Islamabad, Pakistan \\ *qudsia_sw@yahoo.com
}

\begin{abstract}
The paper aims to investigate the gender in higher education andcareer experience of women academicians to understand the factors that undermine their career progression. The objectives of the study are to overview the existing situation of women and men in universities and to identify the barriers that cause the underepresentation of women. Both primary and secondary data was used in the study.Questionnaire (Quantitative method )was used to collect the data. The sample of the study consists of 120 women academician of three universities. The sample universities were AIOU, AJ\&K and FJWU. Data was analysed through percentage,tabulation and graphs. The paper examined the factors such as work/family conflict, exclusion of women from policy formulation,facilities provided by organization, attitude of male superior and colleagues and difficulties to exercise authority over male.The findings show that work/family conflict and difficulties to exercise authority, exclusion of women from policy formulation are negatively impact on women's career progression. This study provides an opportunity to develop an insight into the issue of women's representation in academic and administrative positions in universities. The findings of this study may provide information to different working organizations. There are different projects and programs of ministry of education, ministry of women development. This research would be beneficial both for public and private universities. The study might serve to strengthen efforts to implement equal opportunities for women in the universities and encourage women to put themselves forward for appointment to management positions.
\end{abstract}

Key words: Career progression, exclusion, undermine

\section{Introduction}

"Women account half the world's population, perform two thirds of the hour worked receive one tenth of the world's income and have one hundredth of the world's prosperity in their name" (Momsen, 1991, www.bcca.org). Access to education is a sign of women's position in a society. The cultural and economic constraints limit the girl's education. So this low entrance to higher education undermines the representation of women in the management of tertiary education (UNESCO, 1993). UNESCO also declared that gender equality should be a key items on the agenda from 2008-2013.There is a big difference between the status of women and men in Pakistan. But these differences remain without any major change. According to global gender gap report (world economic Forum, 2011) Pakistan is ranked 134 out of 135 in the economic opportunities participation and 127 in educational attainments. The Beijing report also noted that Pakistani women continued to face patriarchal structure. According to Human Development report 2008 "Pakistan ranks 136 on a list of 177 countries comes under the band of medium human development countries".The literacy rate of women generally is $24 \%$ as compared to $49 \%$ for males". "And among the illiterate population $60 \%$ are women. The $70 \%$ Girls are without basic education opportunities". "In Pakistan literacy rate is $24 \%$ as compared to $38 \%$ in India and $78 \%$ in Srilanka". The facilities for women in tertiary education are also low. "The share of urban women in related professional jobs was about $20 \%$ and about $5.4 \%$ employees of federal are women who are too low". Women in academic position are encouraging but low in administrative positions. Only $27 \%$ women reach tertiary level education and women are still long way from participating in same footing as men (UNESCO, 2002). Women professors are a minority group and women vice chancellors and presidents are still a rarity.

cultural values and cultural stereotypes which see women as vulnerable and in need of protection, domestic role are again in evidence in the restrictions placed on girls within the formal education system(Dines, 1993). Beijing Plate form calling for government to ensure women's equal access to and full participation in power structures, decision-making and leadership (Beijing Platform, 1995, CEDAW).Access to higher education is accompanies by underrepresentation of women in traditional 
female studies. Mostly the women adopt the professions of teaching and health. But their ratio in the management of these departments is low. Social and cultural barriers prevent women to take part in managerial positions. Despite the impressive increase of women in workforce, they continuous to be underrepresented in managerial positions of university. Some exceptional women have broken the concept of glass ceiling and have obtained executive level positions(Wentling\& Thomas, 2007).In Pakistan total associate professors/readers/principal lecturers are 244 out of which the percentage of women associate professors are $21(8.6 \%)$ women and 223(91.4\%) men while in India total associate professors/reader/principal lecturers are 2891 out of which 588 (20.3\%) women and 2303(79.7\%) men and in Bangladesh total associate professors/readers /principal lecturers are 498 out of which $99(19.9 \%)$ are women and 399(80.1\%) were men. The percentage of women associate professors in Pakistan is lower than the Bangladesh and India (Lund Survey, 1998).The objective of the study is to identify the factors that cause the underrepresentation of women in management.

\section{Literature Review}

Chitnis (1993) indicate that although women held positions in management of higher education, but their representation is extremely small and it is highly skewed in term of their discipline-wise distribution as well as their geographical location. UNESCO (2002) focused gender management system for higher education sector to achieving gender equity within the system. Gender mainstreaming in higher education management is bringing greater gender equality. Lacy, Lucinda \& Caroline (1998) find that slowing in growth of women in management positions is the bias against women, bias include that women cannot do adequate job or assumptions that women do not want the job and women are not serious about their career. But male dominated culture restricting them.ILO (2004) identified that one of the way to break the glass ceiling and improve women's opportunities in the labor market is to develop gender-sensitive human resource strategies, including networking, career tracking mentoring and succession planning. Unbiased recruitment and promotion procedures and programs that allow a better balance between work and family are vital for attracting skilled professional women. Pakistan Statistical pocket book govt (2005-06) focused on the issue of greater focus on technical, vocational and professional education, expanding enrollment in higher education. Now enrollment in tertiary education is $2.5 \%$.Benshcops\&Brouns (2003) indicate that right to some employment opportunities, including the application of some criteria for selection in matters of employment, sometime indirect discrimination via a conceptual construction that is itself gendered.ILO (2004) cultural and social attitudes towards what constitutes male or female jobs results in occupational segregation although the extent of problem varies from country to country and from job to job. As far as women's share of managerial positions is concerned the rate of progress is slow and uneven.

Govt. of Pakistan (2005) identified that that percentage distribution of employed persons as legislators, senior officers and manager for the year 2003-04 was $1.4 \%$ for female and $13.5 \%$ for male. Ruth(2005) indicate significant differences in opinions about and perception of the composition and distribution of academic work, it is such difference that effect the achievement of equity and more females than males felt teaching should be evenly distributed and difference is even more significant for administration, academia reflects the larger social condition in which women's work goes unrecognized. Singh (2003) identified that administrative leadership in higher education remains the domain of men and the proportion of women decreases significantly as women moves up to educational and occupational ladder. Onokala \& Onah (1998) have examined the effect of institutional culture on recruitments, promotion and appointments of women to academic and administrative positions. Women are appointed to higher post if they are qualified and capable. Women are continued to be underprivileged by deeply entrenched organizational and societal obstacles and by progression system that largely depend on the publication of candidate (Foster, 2001).Neale \&Ozkanli (2010) indicate that presence of women in higher academic positions was found to be crucial due to organizational barriers. Beson \& Vimol (2005) \&Chesterman (2000), Thomas (2002) agreed with Neale \&Ozkanli (2010) that organizational factors support many of these obstacles. Women were found to be underrepresented in administration and encountered substantial hurdles in attainment of administrative positions. Structural factors supported number of these obstacles. Modifications in laws were recognized as an approach to the advancement of women's career. Structural elements were the dominant hurdles for the women in rising top educational administrative and managerial positions (Neale \&Ozkanli, 2010, Amondi, 2011).UNESCO (2002) in area of higher education, both in teaching and management women are still long way from participating on the same footing as men. Women have made some progress in achieving parity in teaching but grossly underrepresented in higher education management. Al-Lamki(1999) indicate that some of the primary 
resisting forces to women in management related to cultural and traditional values coupled with traditional stereotypes on the status and role of women, other resisting forces to women in management include limited opportunities in higher education, discriminatory appointment and promotion policies, attitude of male bosses and male dominated domain. Statistical department of Pakistan (2005) identified that that percentage distribution of employed persons as legislators, senior officers and manager for the year 2003-04 was 1.4\% for female and 13.5\% for male. CEDAW (1995) calling for government to ensure women's equal access to and full participation in power structures, decision-making and leadership. Due to family commitments, women put their career on hold (Foster, 2001). Flechl (2009) identified that how women manage their work-life balance. The findings indicated that there are some historical and cultural issues as well as individual conditions which make it hard to combine work /life. Women manage their time efficiently, but managing several roles is a big challenge which needs sophisticated solutions. Women require support and help from their family, partners and companies. It was suggested that when women are satisfied from their work/life balance, it has good impact on the performance of women.

\section{Methodology}

The women from three universities from academic and administrative were contacted and approached personally to fill up the questionnaire. The sample consists of $1 / 3^{\text {rd }}$ of women from lecturer, assistant professors and associate professors in each university while the women in Academic administrative level are in low numbers and include all women Academic administrative level managers such as Professors, Dean, HOD and Chairpersons. The questionnaire was prepared in two parts. In the beginning by asking basic questions about age, marital status, children, education and occupation of respondent and her spouse were obtained to understand the socio-economic background.

\section{Analysis}

Table 1: Socio-Economic Profile

\begin{tabular}{llll}
\hline Demographic factors & Division & No. 120 & Percentage \\
\hline Age & Less than 40 & 52 & 43.33 \\
Marital status & more than 40 & 68 & 56.66 \\
& Married & 88 & 73.33 \\
\multirow{3}{*}{ Age. of children } & Single & 32 & 26.66 \\
& Less than 5 years & 37 & 30.83 \\
& More than 5 years & 43 & 35.83 \\
\hline
\end{tabular}

Age: Age is an important factor to know about the involvement of younger generation in managerial positions. The frequency and percentage distribution for age suggests that large proportion of women in university management $(56.66 \%)$ falls in age group of more than forty. It helps us to show which generation is dominant in managerial activities.

Marital status: The marital status of women is divided into two categories i.e. married and unmarried. A large percent of respondents are married as $73.3 \%$. And only $26.66 \%$ are unmarried.

No. of children: It is believed that child care is the responsibility of women. In so many case women stresses related to their children especially small children. But in this study $35.83 \%$ women have their children with an age of more than 5 years while $30.83 \%$ have children with an age of less than five years. While, eight respondents have no children, including newly married women.

Table 2: Educational Qualification

\begin{tabular}{llll}
\hline Factor & Division & Frequency 120 & Percentage \\
\hline Educational & Post graduate & 78 & 65 \\
qualification & MPhil & 19 & 15.83 \\
& PhD & 23 & 19.16 \\
\hline
\end{tabular}

Educational Qualification: Education plays an important role in case of the women manager and it is expected that a sample would have high levels of education Data in Table-2 indicates that large 
proportion of women( $65 \%$ ) of women managers are post graduate, while $15.83 \%$ women having Mphil Degree and $19.16 \%$ are $\mathrm{PhD}$. So the educational level of respondents is high in post- graduation while ratio of women in $\mathrm{PhD}$ and MPhil are low in numbers.

Table 3: Work Experience and Career Profile

\begin{tabular}{lllll}
\hline Factor & Division & & No.120 & Percentage \\
\hline Experience & Less than 5 years & 25 & 20.83 \\
Managerial level & More than 5 years & 95 & 79.16 \\
& Academic & 90 & 75 \\
Salary (in RS.) & Administrative & 30 & 25 \\
Promotion & 15000 & Nil & \\
opportunities & Above 15000 & 120 & 100 \\
& Satisfactory & 73 & 60.83 \\
\hline
\end{tabular}

Job Experience: Job experience is measured in terms of the length of service as less than five years and more than five years. In the table 20.83 percent of women managers have less than five years of experience. It is found that $79.16 \%$ of the women managers have more than 5 years of experience.

Managerial level: Distribution of managers by management level shows that women managers are concentrated mainly in academic level. As in this study, $66.66 \%$ of the total sample size belongs to academic level management and $33.33 \%$ to the administrative level management.

Salary: All sample size has salary more than Rs.15000.

Promotion: As regards to promotion very low numbers of women reach the top level. But data in this table shows that $60.83 \%$ of women showed their satisfaction on promotion policy while $34.16 \%$ showed dissatisfaction on promotion. Majority showed that promotion is not a problem in women's participation in administrative level.

Family background: The influence of parents and their occupation are significant factor that generate aspiration. In this study $73.33 \%$ of women are married so the background of their husband as their education and occupation has a bearing on the job of wife as well as career expectations for accepting administrative jobs. Family background for women managers has been assessed in term of her husband's education and occupation.

Table 4: Educational and occupational background of husband

\begin{tabular}{llll}
\hline Factor & Division & No. 88 & Percentage \\
\hline Husband's education & Undergraduate & 2 & 1.66 \\
& Graduate & 12 & 10 \\
& Post graduate & 56 & 46.66 \\
& Mphil & Nil & Nil \\
& Phd & 18 & 15 \\
Husband's occupation & Service & 63 & 71.59 \\
& Self-employed & 25 & 28.40 \\
\hline
\end{tabular}

Educational background: The data in the table shows that majority respondent's husband is educated. As in Table $46.66 \%$ of husbands of respondents are postgraduate while $15 \%$ are Phd, $10 \%$ are graduate and only $1.66 \%$ are undergraduate. It is observed that education level of husband of the respondent is very high...The educational background of husband may also play an important role in forming the career expectations of wife. In our male dominated society women have to depend on the will of their husband. Educational career of wife is influenced by the will of husband. 
Occupation: While assessing the occupational background of the respondent's husband, it is seen that the largest majority of husbands as $71.59 \%$ are service holders while $28.40 \%$ are engaged in self-business.

Table 5: Effect of Job on Women

\begin{tabular}{llll}
\hline Factor & Division & Frequency & Percentage \\
\hline Effect of job on personal life & Sacrifice & 57 & 47.5 \\
& Stress & 37 & 30.83 \\
& No effect & 26 & 21.66 \\
Influence of work on family & No influence & 46 & 38.33 \\
& Little effect & 74 & 61.66 \\
\hline
\end{tabular}

Effect of job on personal life: The working women also bear the effect of job on their personal life because they have to look after home, children and husband. The $47.5 \%$ respondents accepted that they have to sacrifice in their life while $30.83 \%$ feel stress of job and $21.66 \%$ have no effect on their job and these include unmarried women.

Influence of Work on Family: The working women have also effect of job on their family. The $61.66 \%$ have little effect of job on their family and $38.33 \%$ have no influence. Sometime they feel they do not have sufficient time to attend to family get together or social functions.

Table 6: Attitude of male superior \& colleagues

\begin{tabular}{|c|c|c|c|}
\hline Factor & Division & Frequency & Percentage \\
\hline Attitude & Cooperative & 68 & 56.66 \\
\hline superiors & Non-cooperative & 6 & \\
\hline & Comparatively & 46 & 38.33 \\
\hline & Cooperative & & \\
\hline Attitude of & Cooperative & 52 & 43.33 \\
\hline colleagues & Non-cooperative & 15 & 12.5 \\
\hline & $\begin{array}{l}\text { Comparatively } \\
\text { cooperative }\end{array}$ & 53 & 44.16 \\
\hline Difficulties & Yes & 50 & 41.66 \\
\hline $\begin{array}{lr}\text { exercise } & \text { authority } \\
\text { over } & \text { male } \\
\text { subordinates } & \end{array}$ & No & 70 & 58.33 \\
\hline
\end{tabular}

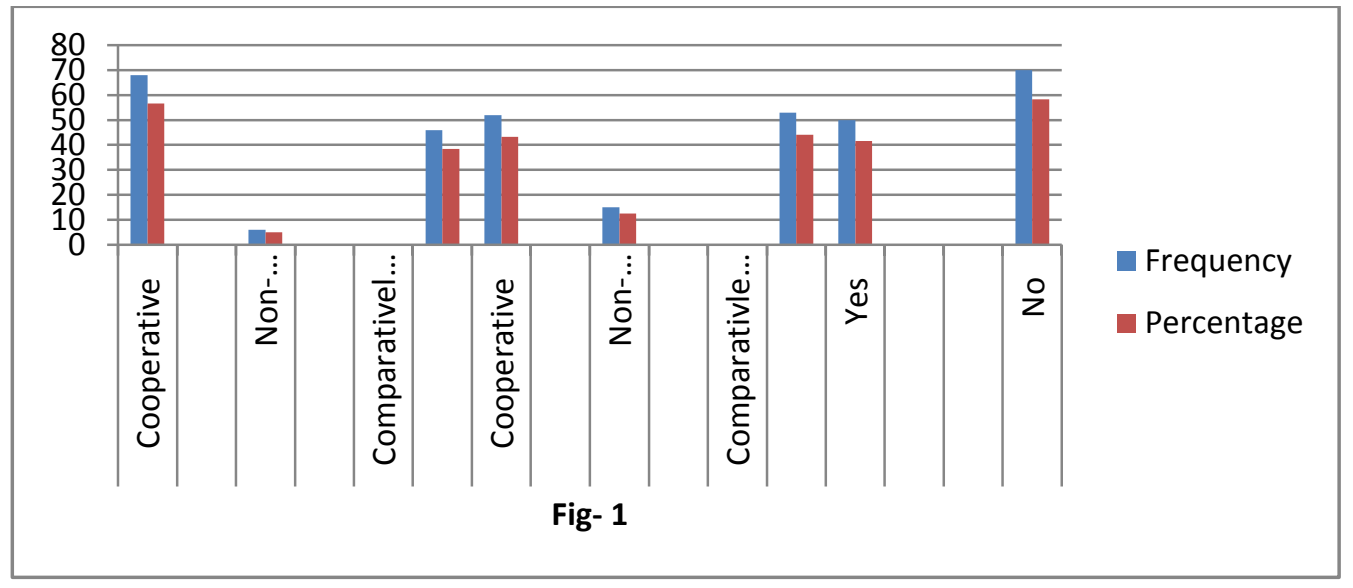

Attitude of male superiors: Due to social and cultural factors it is difficult for women to work with men because they consider the working women first the women then the professional employee. So the acceptance of women is critical. Majority of respondents (68\%) response is cooperative while38\% comparatively cooperative and $5 \%$ respond non-cooperative. It means situation is quite better in universities. Most of the respondents have good relations with their superior. 
Attitude of male colleagues: In order to assess the attitude of male larger number's $44.16 \%$ response is comparatively cooperative and $43.33 \%$ cooperative while non-cooperative ratio is $12.5 \%$. Sometime

Difficulties to Exercise authority over male: Ours a male dominated society, so mostly male subordinates do not accept women as their head. It is measured in term of Yes and No. 58.33\% respondents said they do not feel difficulty to exercise authority over male subordinates while $41.66 \%$ said yes they feel difficulty to exercise authority over male subordinates. Sometime the male subordinates hesitate to take order from the male superiors especially from female managers.

Table 7: Exclusion of Women from Policy Formulation

\begin{tabular}{llll}
\hline Factor & Division & Frequency & Percentage \\
\hline Women managers & Agree & 33 & 27.5 \\
are excluded from & Strongly agree & 24 & 20 \\
policy & 35 & 29.16 \\
formulation & Disagree & 12 & 10 \\
& Strongly disagree & 16 & 13.33 \\
& Neither agree nor disagree & 16 & \\
\hline
\end{tabular}

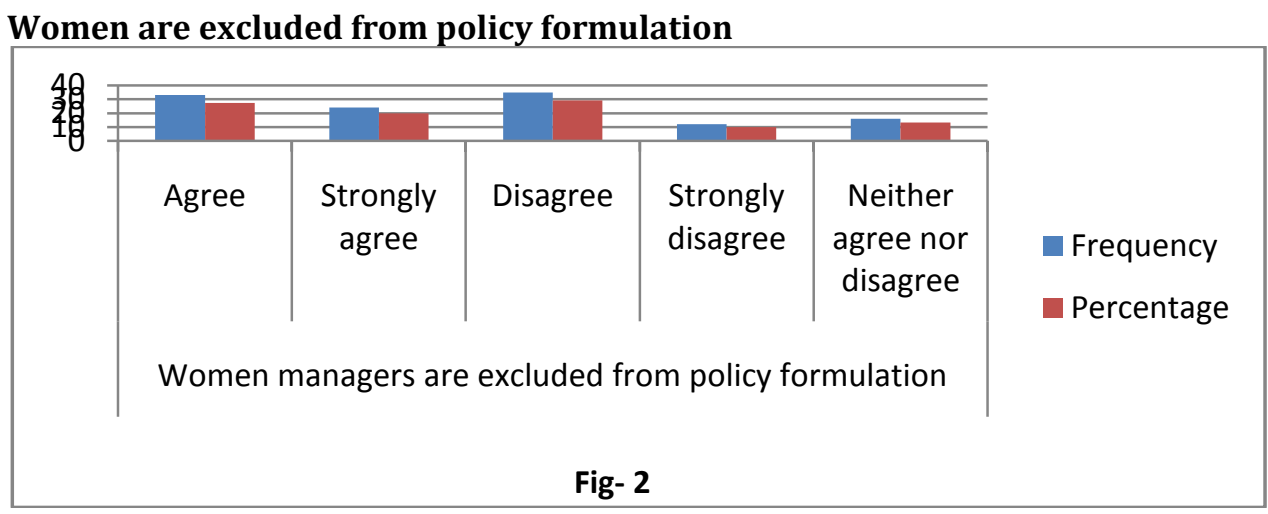

Women's share of decision-making and leadership is small in most part of the world shows no clear trends towards improvement. Researcher used the Likert scale to assess the response of Women about their exclusion from policy formulation. But $27.55 \%$ respondents agreed that women are excluded from policy formulation and $29.16 \%$ disagree while $20 \%$ strongly agree that women are excluded from policy formulation while $13.33 \%$ are neither agree nor disagree with this statement.

Table 8: Facilities provided by organization

\begin{tabular}{llll}
\hline Factors & Division & Frequency & Percentage \\
\hline $\begin{array}{l}\text { Facilities provided by } \\
\text { organization (daycare }\end{array}$ & Yes & 62 & 51.66 \\
Centre, transport etc.) & No & 58 & 48.33 \\
\hline
\end{tabular}

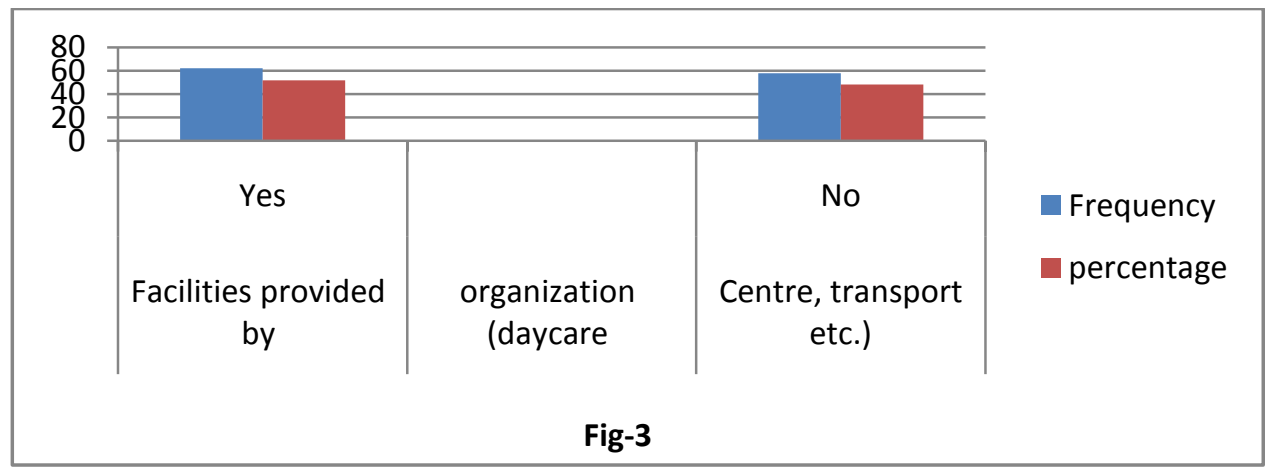


Special facilities provided by organization: Women have the responsibilities of home and office. The level of the facilities is measured by Yes and No. The respondents who say yes are $512.66 \%$ that organization is providing crech facilities while $48.33 \%$ say no. The purpose is to assess the factors that can affect the progress of working women. As indicated that three universities has been selected as a sample in women university (FJWU) the representation of women is satisfactory as compare to other two universities (co-education).

Effect of job on personal life: The working women also bear the effect of job on their personal life because they have to look after home, children and husband. The majority of respondents accepted that they have to sacrifice in their life

Influence of Work on Family: The working women have also effect of job on their family. Sometime they feel they do not have sufficient time to attend to family get together or social functions.

Attitude of superiors, colleagues and subordinates: While $56.66 \%$ of the respondents feel that the attitude of their superior is cooperative. $44 \%$ of opinion that attitude of their colleagues is comparatively cooperative. Sometimes male subordinates hesitate to follow the order from female boss.

Women are excluded from policy formulation: It is seen $39.16 \%$ respondents disagree with this statement while $47.5 \%$ are agreed that women are excluded from policy formulation and decisionmaking. Mostly decisions are made at top level so they feel neglected at a time of policy formulation.

Increase in Participation: By asking the question to the respondents how their participation in Management increase and improve, the $40 \%$ of the respondents think that it can increase through awareness among men and women, While $30 \%$ focused on education and $11.6 \%$ focused on training, only $1.6 \%$ focused on quota and $15.8 \%$ considered that all these factors involve in increasing the women's participation in management.

Special facilities: It is the important factor that women face in their job. The respondents who say yes are $51.6 \%$ while $48.3 \%$ said no. The FJWU is providing daycare facilities and also medical facilities in university while In AIOU the staff has day care Centre on self-help basis but university provided them transport facilities. And in AJ\&K there is not any such facility especially daycare Centre.

\section{Conclusion}

The findings show that women are in low numbers in administrative level in the universities. The results indicate that there are many factors involve in the underrepresentation of women in management. The findings show that Due to social and cultural factors it is difficult for women to work with men because they consider the working women first the women then the professional employee. The attitude of male towards women manager was found to be comparatively cooperative and ours a male dominated society, so mostly male subordinates do not accept women as their head. It was found. Sometime the male subordinates hesitate to take order from the male superiors especially from female managers. The working women also bear the effect of job on their personal life because they have to look after home, children and husband. They have to sacrifice in their life. The working women have also effect of job on their family. Sometime they feel they do not have sufficient time to attend to family get together or social functions. Women's share of decision-making and leadership is small in most part of the world shows no clear trends towards improvement. Women are also excluded from policy formulation.

Recommendations: Women are about $50 \%$ of population and should ensure their full participation in economic development. The appointment and promotion policies should be fair and unbiased, choosing the right person for right job. Human resource policies should be established by government to execute the recruitment, T\&D of Pakistani women to management positions. Involve the women in planning and decision-making, it will encourage the representation of more women. Equal access to education and employment opportunities and implement the quota. Eliminate gender discrimination, Scholarships and fellowships opportunities for women in higher education. Introduce training courses for women of academic and administrative level for capacity buildings and awareness campaigns to reduce gender inequality in education and employment. 


\section{References}

Amondi, 0. (2011). Representation of women in top educational management and leadership positions in Kenya. Journal of advancing women in leadership, 31, 57-68.

Al-lamki, M. S. (1999). Paradigm Shift: A perspective on Omani women in management in the sultanate of Oman. Advancing women in leadership journal, 2(1), 1-25.

Benson, J., \& Vimol, W. (2005). Asian women managers' participation, barriers and future prospects. Journal of pacific business review, 11(2), 283-291.

Benschop, Y. \& Brounds, M. (2003). Crumbling ivory towards: Academic organizing and its gender effects. Gender, work and organization, 10(2), 194-212.

CEDAW. (1995). UN treaty Series, 1249, 13.

Chitnis, S. (1993). The place of women in the management of higher Education in India. In

Dines, E. (1993). Women in higher Education management, Paris UNESCO Commonwealth Secretariat.

Chesterman, C. (2000). Women's Executive Development in Australian higher Education: The WEXDEV Model. Paper presented at NAWE conference, New Orleans.

Government of Pakistan. (2005). Pakistan Education Statistics 2005, Academy of Education planning and Management, Ministry of education.

Foster, N. (2001). A case study of women academics views on equal opportunities, career prospects and work family conflicts in UK University. Journal of career development international, 6, 28-38.

Flechl, V. (2009). Work Life Balance - A comparative Study of Women in Senior Management Positions in Austria, Denmark and Great Britain. ebook ISBN 978-3-640-54822-4.

ILO. (2004). Tripartite On Breaking Through the Glass ceiling: Women in management, ILO Geneva. December 15-19 www.ilo.org.

Lund, H. (1998). A Single Sex Profession? Female Staff numbers in commonwealth universities, London. Commonwealth Higher education Management service.

Lamki, M .S. (1999). A perspective on Omani Women In Management in The Sultanate of Oman. $A W L$ Journal, 2(2).

Lacy, S. \& Lucinda, D. \& Caroline, M. (1998). Women in Newspaper Newsroom management, WJMCR 1:2

Mamsen, J. (1991). Women in the Third World. Routledge. London.

Neale, J. \& Ozkanli, O. (2010). Organizational Barriers for Women in Senior Management: A Comparison of Turkish and Newzealand Universities.

Onokala, C. P. \& Onah, O. F. (1998). Women in academic positions in the universities in Nigeria. Special project of the association of African universities.

Ruth, D. (2005). Gender and Perceptions of Academic Work in South Africa. JHEA/RESA, 3, 57-85.

Singh, J. K. S. (2003). Prioritising Gender Equality in Higher education management, Part Three Tertiary Education, Commonwealth Education Partnerships.

Thomas, A. (2002).Women in academic administration. Sage online journal http//ema.sagepub.com.

UNESCO. (2002). Women and Management in Higher Education. A good Practice Handbook.

U.N. (2000). Women 2000: Women and Decision-Making, www.undp.org.

UNESCO. (1993). Women in Higher Education Management. Commonwealth Secretariate.

Wentling, R. \& Thomas, S. (2007). The career Development of Women executives In information Technology. Journal of Information Technology Management, XVIII (1).

World Economic Forum. (2011). Global Gender Gap Report, 2011. www.weforum.org. 